\title{
Estudo cefalométrico das alterações no perfil facial em pacientes Classe III dolicocefálicos submetidos à cirurgia ortognática bimaxilar*
}

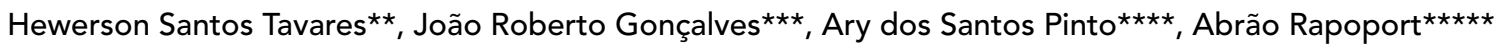

\begin{abstract}
Resumo
O presente estudo avaliou as modificações no perfil facial de 15 pacientes portadores de má oclusão Classe III esquelética que foram submetidos a tratamento ortodôntico pré-cirúrgico e cirurgia ortognática bimaxilar estabilizada com fixação rígida. Oito pacientes foram submetidos à mentoplastia. Foram utilizadas telerradiografias pré-cirúrgicas (T1) e pós-cirúrgicas (T2) com um intervalo mínimo de 6 meses. Foram analisados deslocamentos horizontais e verticais em pontos do tecido ósseo e tecido mole. Foi realizada uma comparação entre os casos tratados com e sem mentoplastia (teste $t$ ) mostrando não haver diferenças entre os grupos. A regressão linear múltipla evidenciou uma correlação significante no sentido horizontal para os pontos Pg e Pgm e vertical para os pontos Me e Mem. Foi encontrada baixa correlação para movimentos no sentido horizontal nos pontos Sena e A, e para os pontos $\mathrm{Pn}, \mathrm{Sn}$ e Ph. No sentido vertical, os deslocamentos mais evidentes foram entre os pontos Pg, Gn e Me e Sena e A, porém com correlações de baixa intensidade.
\end{abstract}

Palavras-chave: Perfi facial. Cirurgia ortognática. Classe III.

\section{INTRODUÇÃO}

Os principais objetivos da cirurgia ortognática são obter oclusão normal e melhorar a estética facial ${ }^{41}$. O tratamento da má oclusão Classe III esquelética envolve um planejamento ortodôntico pré-cirúrgico que tem o objetivo de correção de deficiências de comprimento do arco dentário, eliminação de rotações e outros procedimentos envolvendo o alinhamento e nivelamento dos arcos, características comuns da terapia conven- cional, que não são executados em todos os casos. A mecânica intra-arcos em casos cirúrgicos deve ser planejada a fim de obter as relações adequadas de caninos e molares ${ }^{28}$. A obtenção desses objetivos requer que os dentes estejam posicionados em ideal relação espacial com as bases ósseas ${ }^{23}$, estes cuidados fazem parte do planejamento ortodôntico pré-cirúrgico e devem ser levados em consideração, visto que a estabilidade do tratamento cirúrgico depende destes fatores ${ }^{2,6}$.

*Resumo da dissertação de mestrado interinstitucional apresentada ao curso de pós graduação em Ciências da Saúde do Hospital Heliópolis São Paulo e Universidade Estadual Paulista - UNESP/Araraquara.

** Mestre em Cirurgia de Cabeça e Pescoço - Hospital Heliópolis, São Paulo.

*** Professor Assistente Doutor do Departamento de Clínica Infantil-Ortodontia, UNESP-Araraquara.

**** Professor Livre Docente do Departamento de Clínica Infantil-Ortodontia, UNESP-Araraquara.

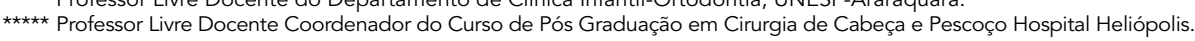


Nos pacientes portadores de má oclusão esquelética Classe III alguns pontos cefalométricos podem estar comprometidos pelo problema pré-existente. Em alguns casos é possível identificar alterações cefalométricas como: encurtamento da base do crânio, de modo que o ponto "násio" pode estar localizado em uma posição mais posterior, ou ainda, a altura facial posterior pode estar diminuída e portanto o ponto "pório" pode estar localizado mais inferior tornando inadequadas as mensurações angulares e lineares que utilizam estas estruturas como referência ${ }^{15}$. As características morfológicas associadas a este tipo de má oclusão devem ser levadas em consideração no planejamento ortodôntico e cirúrgico. Em alguns casos, parte das análises e medidas cefalométricas são abandonadas levando em consideração todos os dados obtidos na análise facial e as expectativas do próprio paciente ${ }^{2,3,5}$. É necessário que, antes da cirurgia, sejam estabelecidos o torque correto para incisivos e molares que, se corrigidos após, podem ser alvo de recidiva ${ }^{29,46}$. No tratamento ortodôntico pré-cirúrgico da má oclusão de Classe III, os incisivos inferiores estão freqüentemente retroinclinados enquanto os superiores estão inclinados para vestibular ${ }^{35,61}$.

A atresia maxilar transversal é um problema freqüente e deve ser planejada no início da terapia ortodôntica pré-cirúrgica a estratégia que será abordada na cirurgia, nesses casos destacamos as cirurgias de expansão maxilar e segmentação maxilar em dois ou três segmentos. As alterações na estética facial são obtidas através dos reposicionamentos cirúrgicos realizados nos tecidos duros subjacentes ${ }^{1,4,7,10,12,18,19,22,38}$. O contorno facial nem sempre obedece à mesma proporção de deslocamento do tecido ósseo. Isso ocorre devido às variações em espessura e tônus de uma região da face para outra e de indivíduo para outro ${ }^{10,22,24}$. Os tecidos moles podem estar firmemente aderidos em uma região e livres em outras. Aqueles que estão firmemente aderidos exibem alterações mais consistentes enquanto os menos aderidos apresentam menor modificação devido à sua elasticidade ${ }^{39,61}$.
A cirurgia do tipo "Le Fort I "para correção de displasias esqueléticas tem efeito sobre o nariz e o lábio superior. A literatura descreve alterações nasais e labiais que ocorrem após a cirurgia maxilar, tais como alargamento da base alar, elevação do ápice nasal, achatamento e estreitamento do lábio superior ${ }^{8,10,11}$.

Estas alterações pós-operatórias são decorrentes de modificações na anatomia regional, seguidas ao reposicionamento esquelético e retração muscular, seguida de fibrose cicatricial, que são efeitos resultantes destes procedimentos na pele e no tecido sub-cutâneo, que todavia podem ser controlados desde que estejam previstos no planejamento $\mathrm{o}^{20,26,34,36,50,55}$. O reposicionamento superior da maxila seguido de avanço, utilizado no tratamento ortodôntico-cirúrgico, tem muitas indicações no tratamento de casos de cirurgias bimaxilares em pacientes portadores de má oclusão esquelética Classe III ${ }^{21,54,58}$, podendo ser utilizado para o fechamento de mordidas abertas, correção do excesso vertical de maxila, alterações de plano oclusal $^{61}$ e em pacientes que tiveram crescimento vertical.

Na última década, o uso da osteotomia tipo Le Fort I tem se tornado comum e seus efeitos sobre os tecidos moles circundantes têm sido bem documentados. As alterações de tecidos moles associadas à impacção maxilar são: aumento do ângulo nasolabial, aumento da largura da base alar, diminuição do comprimento do lábio superior, e alterações na posição labial quando é associada ao movimento ântero-posterior e vertical ${ }^{19}$.

\section{OBJETIVO}

Avaliar as alterações horizontais e verticais de pontos no perfil facial resultantes de tratamentos cirúrgicos bimaxilares com mentoplastia, associada ou não, em pacientes dolicocefálicos portadores de má oclusão esquelética Classe III.

\section{MATERIAL E MÉTODO}

Para o presente trabalho, foi selecionada uma 
amostra composta por 30 telerradiografias em norma lateral de 15 indivíduos caucasianos de ambos os gêneros submetidos a tratamento ortodôntico e cirúrgico, sendo que 8 destes foram submetidos a mentoplastias. Foram consideradas apenas as telerradiografias em norma lateral da fase pré-cirúrgica imediata (T1) e pós-cirúrgica tardia (T2) (Fig. 1, 2). Em toda a amostra, as telerradiografias em norma lateral pré-cirúrgicas imediatas foram realizadas no máximo sete dias antes da cirurgia, e telerradiografias em norma lateral da fase póscirúrgica tardia no mínimo seis meses após o procedimento cirúrgico. Estes indivíduos foram selecionados dentre aqueles que não sofreriam mais alterações de espessura labial com o aumento da idade e que não haviam passado por tratamento cirúrgico prévio. Toda amostra foi tratada com aparelhos pré-ajustados (arco reto) e todos os pacientes receberam contenção pós-ortodôntica.

Todos os pacientes foram diagnosticados como portadores de má oclusão esquelética Classe III de Angle, posição da maxila em relação à base do crânio ângulo SNA, posição da mandíbula em relação à base do crânio ângulo SNB, relação dentária maxilo-mandibular e em relação ao ponto násio, ângulo ANB e padrão esquelético através do ângulo SNGoMe (Tab. 3).

\section{Método}

\section{Demarcação dos pontos cefalométricos}

Foi adaptada uma folha de papel de acetato transparente "ultraphan" (Cephalometric Tracing Paper - GAC), tamanho 8" x 10" sobre as radiografias iniciais e finais dos indivíduos selecionados para amostra. Os pontos cefalométricos escolhidos para a análise foram demarcados com a ajuda de um negatoscópio, com lapiseira $0,3 \mathrm{~mm}$, em sala escurecida.

Os cefalogramas foram digitalizados em uma mesa digitalizadora Numonics AccuGrid utilizando um microcomputador IBM compatível e o programa "Dentofacial Planner Plus 2.0" especial-
Tabela 1 - Divisão da amostra segundo gênero.

\begin{tabular}{ccc}
\hline $\begin{array}{c}\text { Gênero e tipo de } \\
\text { cirurgia }\end{array}$ & Freqüência & Porcentagem \\
\hline Feminino & 11 & $73,33 \%$ \\
Masculino & 4 & $26,66 \%$ \\
\hline
\end{tabular}

Tabela 2 - Divisão da amostra segundo o tipo de cirurgia.

\begin{tabular}{ccc}
\hline Tipo de cirurgia & Freqüência & Porcentagem \\
\hline C / Mentoplastia & 6 mulheres & $40 \%$ \\
C / Mentoplastia & 2 homens & $13,33 \%$ \\
S / Mentoplastia & 5 mulheres & $33,33 \%$ \\
S / Mentoplastia & 2 homens & $13,33 \%$ \\
\hline
\end{tabular}

Tabela 3 - Caracterização quanto ao padrão esquelético facial.

\begin{tabular}{ccccc}
\hline & Média & D.P. & Mínimo & Máximo \\
\hline SNA & 77,85 & 4,84 & 69,00 & 87,60 \\
SNB & 81,37 & 4,62 & 74,00 & 88,10 \\
ANB & $-3,51$ & 3,09 & $-7,70$ & 2,70 \\
SnGoMe & 39,85 & 5,37 & 30,40 & 49,00 \\
\hline
\end{tabular}

mente adaptado para esta finalidade.

Mensuração das alterações ocorridas com o tratamento cirúrgico do pré para o pós-tratamento

As alterações esqueléticas, faciais e dentárias ocorridas foram mensuradas por projeção dos pontos cefalométricos sobre a linha horizontal e vertical de referência representando respectivamente as coordenadas cartesianas X e Y. A linha horizontal, denominada de eixo $\mathrm{X}$ foi determinada a partir do ponto cefalométrico Sela (S) com inclinação de $7^{\circ}$ para baixo em relação à linha Sela-Násio. A linha vertical, denominada de eixo $\mathrm{Y}$ foi determinada a partir do ponto cefalométrico Sela (S) perpendicularmente ao eixo $\mathrm{x}$. Por meio dos pontos digitados no pré (T1) e no pós-tratamento (T2) foram feitas avaliações das modificações ocorridas no perfil, no que diz respeito à sua posição (deslocamento) no sentido 

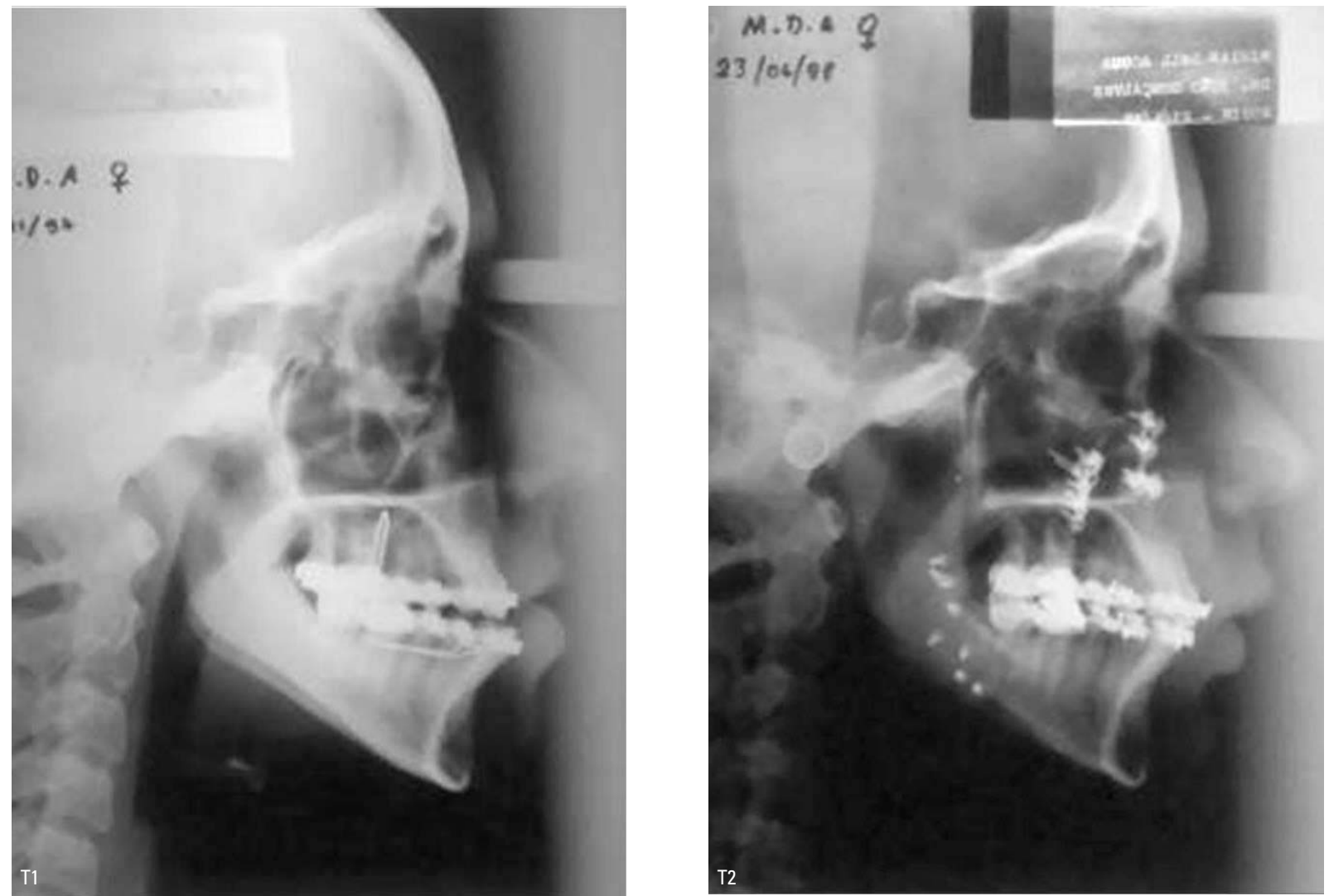

FIGURA 1 e 2 - Telerradiografia em norma lateral pré-cirúrgica imediata (T1) e telerradiografia em norma lateral pós-cirúrgica tardia (T2).

ântero-posterior e vertical, e quando às alterações de espessura. $\mathrm{O}$ efeito do tratamento $(\Delta \mathrm{T})$ foi verificado como sendo a diferença entre as mensurações das duas ocasiões de tratamento (T2-T1).

\section{Metodologia estatística}

Em todos os testes estatísticos empregados neste trabalho foi adotado o nível de 5\% de significância como critério para a rejeição da hipótese nula. Entretanto, procurou-se destacar os casos em que a rejeição da hipótese nula se daria mesmo a um nível menor do que $1 \%$ de significância. Esta avaliação pode ser feita pela observação do valor de probabilidade do teste (valor-p).

\section{Comparação dos tipos de cirurgia}

A comparação dos dois tipos de cirurgia em- pregados: com mentoplastia e sem mentoplastia, quanto ao deslocamento em cada ponto do tecido mole ou do tecido duro, tanto no sentido vertical como no sentido horizontal, foi realizada pelo teste $t$ de Student. Neste caso, a hipótese nula em teste é obviamente a de que o deslocamento médio é o mesmo, independentemente do tipo de cirurgia.

\section{Significância dos deslocamentos}

Foram construídos intervalos de 95\% para a média esperada de deslocamento com a intervenção cirúrgica. Quando esses intervalos incluem o valor zero, significa que não se pode rejeitar a hipótese nula de que os deslocamentos médios esperados são iguais a zero. Este procedimento é equivalente a aplicar o teste $t$ de Student para avaliar a significância do deslocamento em relação ao zero. Entretanto, o intervalo fornece a informação 


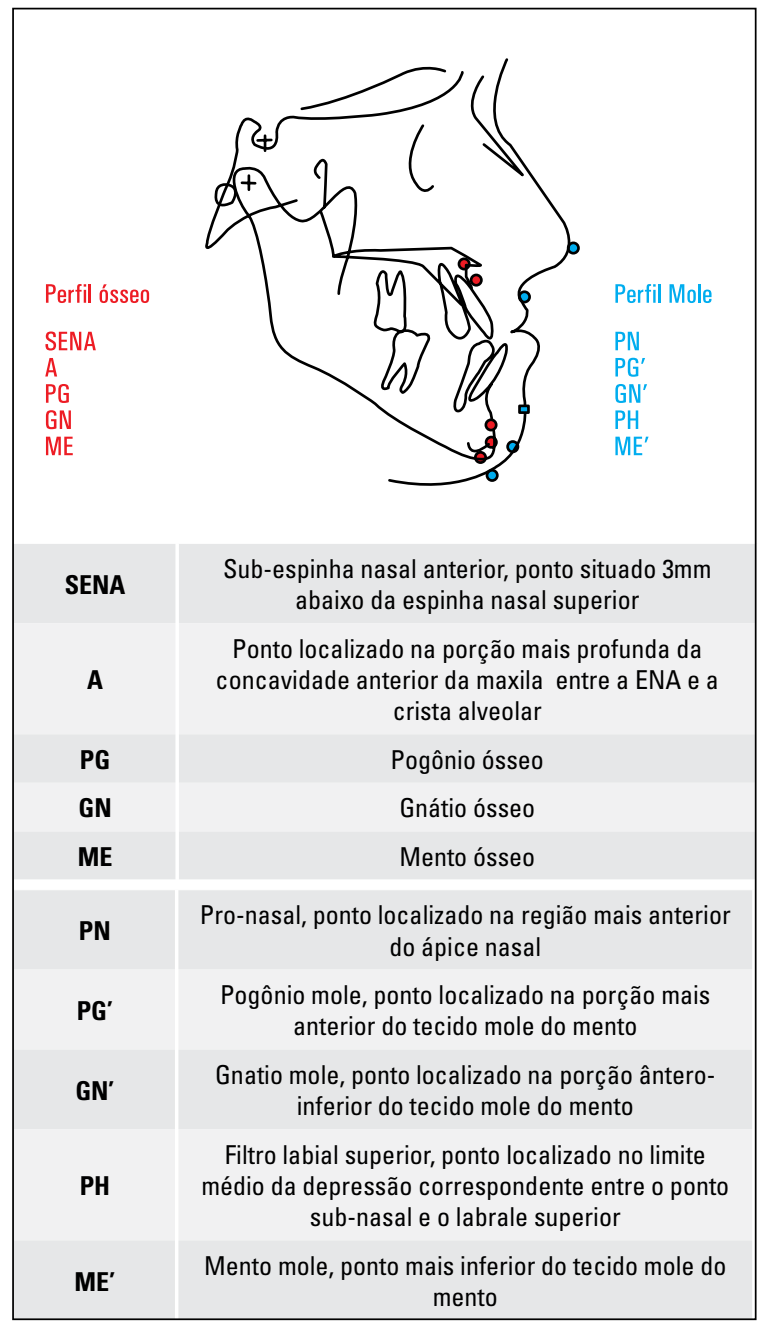

FIGURA 3 - Cefalograma com os pontos avaliados.

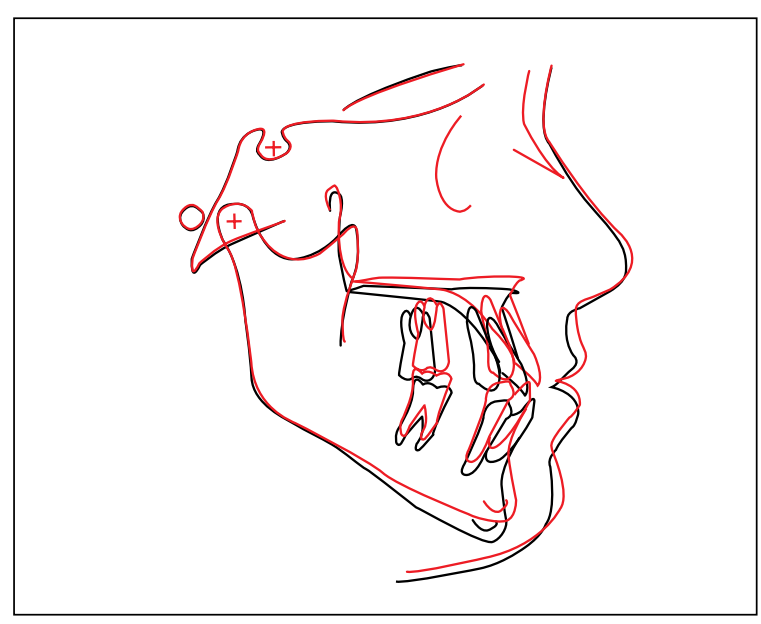

FIGURA 4 - Rotação anti-horária das bases ósseas observada na sobreposição média dos traçados cefalométricos pré-cirúrgicos (preto) e pós-cirúrgicos (vermelho). adicional sobre o valor esperado para a média de deslocamento.

\section{Correlação e regressão}

O coeficiente de correlação de Pearson foi utilizado para determinar o grau de relacionamento das alterações do tecido mole com as alterações do tecido duro. Um valor relativamente menor do que 1 do coeficiente de correlação sugere a falta de uma relação perfeita entre as duas variáveis e pode ser um indicativo de que outras variáveis estão interagindo com elas. Neste caso, a predição de um deslocamento no tecido mole deve ser feita a partir do conhecimento de mais de um deslocamento no tecido ósseo.

Foi empregado o teste $\mathrm{F}$ de regressão linear múltipla para avaliar quais alterações do tecido duro estão mais relacionadas com pontos determinados do tecido mole. A equação de regressão obtida permite a predição dos deslocamentos no tecido mole em função das alterações no tecido duro. Como tentativa de diminuir criteriosamente o número de variáveis do modelo de regressão foi empregado um método stepwise de seleção de variáveis.

\section{RESULTADOS}

Nas tabelas 4 e 5 são apresentadas as médias, desvios padrão (DP) de deslocamentos horizontais (h) e verticais (v) em pontos, respectivamente, do tecido mole e do tecido ósseo da face, obtidos em pacientes submetidos aos dois tipos de cirurgia; a estatística $t$ de Student para comparar as médias de deslocamentos nos dois tipos de cirurgia em cada ponto e o valor de probabilidade (valor-p) correspondente. Observa-se que todos os valores-p são muito maiores do que 0,05 e, portanto, ao nível de $5 \%$ de significância, não há qualquer evidência de que as cirurgias com ou sem mentoplastia produzam deslocamentos médios diferentes. Em vista disso, para fortalecer a análise, os deslocamentos em cada ponto foram agrupados. Assim, o que vem a seguir se refere aos dois tipos de cirurgia indistintamente e, para simplificar a 
linguagem, não será feita distinção desses tipos.

Nas tabelas 6 e 7 são dadas as médias e os desvios padrão (DP) de deslocamentos horizontais (h) e verticais (v) nos pontos em estudo, respectivamente, do tecido mole e do tecido ósseo da face, agora para as medidas de deslocamento resultantes dos dois tipos de cirurgia agrupados. São dados também o limite superior e o limite inferior dos intervalos de $95 \%$ para a média populacional de deslocamento, isto é, a média real que se

Tabela 4 - Média, desvio padrão (DP) de deslocamentos horizontais (h) e verticais (v) em pontos do tecido mole da face, obtidos em pacientes submetidos a dois tipos de cirurgia: com mentoplastia e sem mentoplastia, a estatística $t$ de Student para comparar as médias de deslocamentos nos dois tipos de cirurgia em cada ponto e o valor de probabilidade (valor-p) correspondente.

\begin{tabular}{|c|c|c|c|c|c|c|}
\hline \multirow{3}{*}{ Ponto } & \multicolumn{4}{|c|}{ Tipo de cirurgia } & \multirow{3}{*}{ Estatística $t$} & \multirow{3}{*}{ Valor-p } \\
\hline & \multicolumn{2}{|c|}{ Com mentoplastia } & \multicolumn{2}{|c|}{ Sem mentoplastia } & & \\
\hline & Média & DP & Média & DP & & \\
\hline Pn_h & 1,3 & 0,79 & 1,8 & 0,51 & 1,52 & 0,1530 \\
\hline Pn_v & $-2,3$ & 1,45 & $-1,7$ & 2,32 & 0,61 & 0,5496 \\
\hline Sn_h & 3,0 & 1,33 & 2,2 & 1,05 & 1,15 & 0,2701 \\
\hline Sn_v & $-2,1$ & 1,81 & $-3,0$ & 2,65 & 0,75 & 0,4644 \\
\hline Ph_h & 3,7 & 1,75 & 3,4 & 1,51 & 0,38 & 0,7101 \\
\hline Ph_v & $-1,9$ & 1,95 & $-2,4$ & 2,52 & 0,50 & 0,6250 \\
\hline Pgm_h & 4,6 & 4,07 & 5,4 & 2,95 & 0,44 & 0,6662 \\
\hline Pgm_v & $-6,2$ & 4,38 & $-6,0$ & 3,58 & 0,09 & 0,9304 \\
\hline Gnm_h & 5,9 & 5,09 & 7,3 & 4,97 & 0,55 & 0,5906 \\
\hline Gnm_v & $-5,9$ & 4,38 & $-5,7$ & 4,38 & 0,08 & 0,9365 \\
\hline Mem_h & 7,3 & 5,66 & 6,9 & 4,83 & 0,16 & 0,8717 \\
\hline Mem_v & $-5,6$ & 4,82 & $-5,6$ & 3,99 & 0,02 & 0,9830 \\
\hline
\end{tabular}

Tabela 5 - Média, desvio padrão (DP) de deslocamentos horizontais (h) e verticais (v) em pontos do tecido ósseo da face, obtidos em pacientes submetidos a dois tipos de cirurgia: com mentoplastia e sem mentoplastia, a estatística $t$ de Student para comparar as médias de deslocamentos nos dois tipos de cirurgia em cada ponto e o valor de probabilidade correspondente.

\begin{tabular}{|c|c|c|c|c|c|c|}
\hline \multirow{3}{*}{ Ponto } & \multicolumn{4}{|c|}{ Tipo de cirurgia } & \multirow{3}{*}{ Estatística $t$} & \multirow{3}{*}{ Valor-p } \\
\hline & \multicolumn{2}{|c|}{ Com mentoplastia } & \multicolumn{2}{|c|}{ Sem mentoplastia } & & \\
\hline & Média & DP & Média & DP & & \\
\hline Sena_h & 2,88 & 2,11 & 3,39 & 2,66 & 0,41 & 0,6852 \\
\hline Sena_v & $-1,70$ & 4,89 & $-3,73$ & 1,89 & 1,03 & 0,3224 \\
\hline A_h & 2,93 & 2,10 & 4,43 & 2,05 & 1,40 & 0,1855 \\
\hline A_v & $-2,24$ & 4,91 & $-3,64$ & 2,00 & 0,71 & 0,4932 \\
\hline Pg_h & 3,45 & 5,52 & 4,51 & 2,47 & 0,47 & 0,6469 \\
\hline$P g \_v$ & $-4,16$ & 4,69 & $-6,16$ & 2,81 & 0,98 & 0,3453 \\
\hline Gn_h & 3,35 & 8,01 & 5,13 & 1,57 & 0,58 & 0,5748 \\
\hline Gn_v & $-4,84$ & 5,07 & $-6,51$ & 2,78 & 0,78 & 0,4517 \\
\hline Me_h & 2,40 & 9,33 & 5,43 & 0,91 & 0,85 & 0,4102 \\
\hline Me_v & $-4,75$ & 4,58 & $-5,84$ & 2,53 & 0,56 & 0,5855 \\
\hline
\end{tabular}


Tabela 6 - Média, desvio padrão (DP) de deslocamentos horizontais (h) e verticais (v) em pontos do tecido mole da face, os limites do intervalo de $95 \%$ de confiança para o deslocamento populacional, a estatística $t$ de Student para avaliar se os deslocamentos são significativamente diferentes de zero e o valor de probabilidade correspondente.

\begin{tabular}{|c|c|c|c|c|c|c|}
\hline \multirow{2}{*}{ Ponto } & \multirow{2}{*}{ Média } & \multirow{2}{*}{ Desvio Padrão } & \multicolumn{2}{|c|}{ Intervalo de confiança $(95 \%)$} & \multirow{2}{*}{ Valor-p } & \\
\hline & & & LI & LS & & \\
\hline Pn_h & 1,56 & 0,71 & 1,17 & 1,95 & $<0,0001$ & ** \\
\hline Pn_v & $-1,98$ & 1,86 & $-3,01$ & $-0,95$ & 0,0010 & $* *$ \\
\hline Sn_h & 2,61 & 1,22 & 1,94 & 3,29 & $<0,0001$ & $* *$ \\
\hline Sn_v & $-2,52$ & 2,20 & $-3,74$ & $-1,30$ & 0,0006 & ** \\
\hline Ph_h & 3,59 & 1,59 & 2,70 & 4,47 & $<0,0001$ & ** \\
\hline $\mathbf{P h} \_\mathbf{v}$ & $-2,12$ & 2,17 & $-3,32$ & $-0,92$ & 0,0020 & ** \\
\hline Pgm_h & 4,93 & 3,49 & 3,00 & 6,87 & 0,0001 & ** \\
\hline Pgm_v & $-6,11$ & 3,89 & $-8,27$ & $-3,96$ & $<0,0001$ & $* *$ \\
\hline Gnm_h & 6,53 & 4,91 & 3,81 & 9,25 & 0,0001 & $* *$ \\
\hline Gnm_v & $-5,83$ & 4,22 & $-8,16$ & $-3,49$ & 0,0001 & $* *$ \\
\hline Mem_h & 7,13 & 5,11 & 4,30 & 9,96 & 0,0001 & $* *$ \\
\hline Mem_v & $-5,57$ & 4,30 & $-7,95$ & $-3,19$ & 0,0002 & $* *$ \\
\hline
\end{tabular}

Tabela 7 - Média, desvio padrão (DP) de deslocamentos horizontais (h) e verticais (v) em pontos do tecido ósseo da face, os limites do intervalo de $95 \%$ de confiança para o deslocamento populacional, a estatística $t$ de Student para avaliar se os deslocamentos são significativamente diferentes de zero e o valor de probabilidade correspondente.

\begin{tabular}{|c|c|c|c|c|c|c|}
\hline \multirow{2}{*}{ Ponto } & \multirow{2}{*}{ Média } & \multirow{2}{*}{ Desvio } & \multicolumn{2}{|c|}{ Intervalo de confiança (95\%) } & \multirow{2}{*}{ Valor-p } & \\
\hline & & & LI & LS & & \\
\hline Sena_h & 3,11 & 2,31 & 1,83 & 4,39 & 0,0001 & ** \\
\hline Sena_v & $-2,65$ & 3,82 & $-4,76$ & $-0,53$ & 0,0178 & * \\
\hline A_h & 3,63 & 2,15 & 2,44 & 4,82 & 0,0000 & ** \\
\hline A_v & $-2,89$ & 3,78 & $-4,99$ & $-0,80$ & 0,0103 & * \\
\hline $\mathbf{P g} \_h$ & 3,95 & 4,26 & 1,59 & 6,31 & 0,0030 & ** \\
\hline Pg_v & $-5,09$ & 3,93 & $-7,27$ & $-2,92$ & 0,0002 & ** \\
\hline Gn_h & 4,18 & 5,83 & 0,95 & 7,41 & 0,0148 & * \\
\hline Gn_v & $-5,62$ & 4,12 & $-7,90$ & $-3,34$ & 0,0001 & ** \\
\hline Me_h & 3,81 & 6,81 & 0,04 & 7,58 & 0,0478 & * \\
\hline Me_v & $-5,26$ & 3,68 & $-7,30$ & $-3,22$ & 0,0001 & ** \\
\hline
\end{tabular}

espera com a intervenção cirúrgica. Os valores de probabilidade (valor- p) dessas tabelas permitem tomar a decisão, ao nível de $5 \%$ (ou menor), se os deslocamentos médios são significativamente diferentes de zero. Assim, o deslocamento médio será considerado significativamente diferente de zero sempre que o valor-p for menor que 0,05 , indica- do por um asterisco nas tabelas 8 e 9 . Se o valor-p também for menor do que 0,01 , pode-se entender que a evidência de diferença significativa é mais forte e está indicado por dois asteriscos nessas tabelas. Os deslocamentos nos pontos do tecido mole foram sempre significativamente diferentes de zero $(p<0,001)$. Analogamente, também foram 
Tabela 8 - Coeficientes de correlação de Pearson entre deslocamentos horizontais em pontos do tecido mole e do tecido ósseo.

\begin{tabular}{|c|c|c|c|c|c|c|c|c|c|}
\hline \multirow{2}{*}{ Tecido ósseo } & \multicolumn{8}{|c|}{ Tecido mole } & \\
\hline & Pn_h & Sn_h & Ph_h & Pgm_h & & Gnm_h & & Mem_h & \\
\hline Sena_h & 0,04 & 0,04 & 0,26 & $-0,21$ & & 0,14 & & 0,12 & \\
\hline A_h & 0,41 & 0,14 & 0,35 & $-0,02$ & & 0,27 & & 0,19 & \\
\hline $\mathbf{P g} \_h$ & 0,49 & 0,37 & 0,45 & 0,84 & $* *$ & 0,74 & $* *$ & 0,74 & ** \\
\hline Gn_h & 0,45 & 0,34 & 0,36 & 0,80 & $* *$ & 0,68 & $* *$ & 0,67 & ** \\
\hline Me_h & 0,45 & 0,34 & 0,39 & 0,73 & $* *$ & 0,64 & $* *$ & 0,64 & ** \\
\hline Sena_v & 0,37 & 0,08 & $-0,15$ & 0,04 & & $-0,10$ & & $-0,17$ & \\
\hline A_v & 0,38 & 0,02 & $-0,16$ & 0,09 & & $-0,02$ & & $-0,07$ & \\
\hline$P g \_v$ & 0,11 & $-0,08$ & $-0,32$ & $-0,01$ & & $-0,03$ & & $-0,13$ & \\
\hline Gn_v & 0,01 & $-0,21$ & $-0,39$ & 0,09 & & 0,08 & & $-0,02$ & \\
\hline Me_v & 0,21 & $-0,10$ & $-0,32$ & 0,26 & & 0,19 & & 0,06 & \\
\hline
\end{tabular}

* significativo a um nível entre $1 \%$ e $5 \%$.

** significativo a um nível menor do que $1 \%$.

Tabela 9 - Coeficientes de correlação de Pearson entre deslocamentos verticais em pontos do tecido mole e do tecido ósseo.

\begin{tabular}{|c|c|c|c|c|c|c|c|c|c|c|c|c|}
\hline \multirow{3}{*}{$\begin{array}{c}\text { Tecido ósseo } \\
\text { Sena_h }\end{array}$} & \multicolumn{11}{|c|}{ Tecido mole } & \\
\hline & \multirow{2}{*}{$\begin{array}{c}\text { Pn_v } \\
-0,41\end{array}$} & & \multicolumn{2}{|l|}{ Sn_v } & \multicolumn{2}{|l|}{ Ph_v } & \multicolumn{2}{|l|}{ Pgm_v } & \multirow{2}{*}{$\begin{array}{c}\text { Gnm_v } \\
-0,64\end{array}$} & \multicolumn{3}{|c|}{ Mem_v } \\
\hline & & & $-0,48$ & & $-0,46$ & & $-0,54$ & * & & $*$ & $-0,55$ & $*$ \\
\hline A_h & $-0,24$ & & $-0,39$ & & $-0,30$ & & $-0,32$ & & $-0,45$ & & $-0,43$ & \\
\hline $\mathbf{P g} \_\mathbf{h}$ & 0,09 & & 0,19 & & 0,39 & & 0,10 & & 0,13 & & 0,15 & \\
\hline Gn_h & 0,01 & & 0,00 & & 0,21 & & 0,12 & & 0,19 & & 0,17 & \\
\hline Me_h & $-0,14$ & & $-0,17$ & & 0,03 & & $-0,02$ & & 0,05 & & $-0,02$ & \\
\hline Sena_v & 0,57 & * & 0,56 & $*$ & 0,62 & * & 0,73 & $* *$ & 0,77 & $* *$ & 0,78 & $* *$ \\
\hline A_v & 0,61 & * & 0,64 & * & 0,72 & $* *$ & 0,73 & $* *$ & 0,74 & $* *$ & 0,74 & $* *$ \\
\hline$P g \_v$ & 0,54 & * & 0,55 & * & 0,46 & & 0,26 & & 0,34 & & 0,58 & * \\
\hline Gn_v & 0,57 & * & 0,57 & $*$ & 0,51 & & 0,28 & & 0,35 & & 0,63 & * \\
\hline Me_v & 0,54 & $*$ & 0,42 & & 0,41 & & 0,34 & & 0,47 & & 0,73 & $* *$ \\
\hline
\end{tabular}

* significativo a um nível entre $1 \%$ e $5 \%$.

** significativo a um nível menor do que $1 \%$.

significativos nos pontos do tecido duro, mas em alguns pontos, como Sena_v, A_v, Gn_h e Me_h, não houve deslocamento significativo em um nível menor do que $1 \%$.

Os intervalos de confiança, por sua vez, possibilitam a quantificação do deslocamento médio, com base nos pacientes avaliados neste estudo. É claro que o aumento do número de pacientes levaria a uma maior precisão no deslocamento mé- dio real, já que os intervalos de confiança teriam uma amplitude menor. Quando o deslocamento não foi significativo, o intervalo de confiança para a média inclui o zero.

A seguir, foi realizado um estudo das correlações entre os deslocamentos obtidos nos pontos cefalométricos. Na tabelas 8 e 9 são mostrados os coeficientes de correlação de Pearson entre os pontos do tecido ósseo e pontos do tecido mole. 
Tabela 10 - Coeficientes da equação de regressão múltipla obtida por método stepwise de seleção de variáveis para previsão do deslocamento horizontal em pontos do tecido mole em função do deslocamento em pontos do tecido duro e os valores correspondentes de $\mathrm{F}$ e do coeficiente de determinação $\left(R^{2}\right)$.

\begin{tabular}{|c|c|c|c|c|c|c|c|c|c|c|c|c|}
\hline \multirow{3}{*}{$\begin{array}{c}\text { Tecido Ósseo } \\
\text { Intercepto }\end{array}$} & \multicolumn{11}{|c|}{ Tecido mole } & \\
\hline & \multicolumn{2}{|l|}{ Pn_h } & \multicolumn{2}{|l|}{ Sn_h } & \multicolumn{2}{|l|}{ Ph_h } & \multicolumn{2}{|l|}{ Pgm_h } & Gnm_h & \multicolumn{3}{|c|}{ Mem_h } \\
\hline & 0,819 & * & 2,196 & ** & 1,902 & * & 2,228 & $* *$ & 1,420 & ns & 3,462 & ns \\
\hline Sena_h & $-0,293$ & ns & & & & & & & 0,512 & ns & & \\
\hline A_h & 0,443 & $* *$ & & & & & & & & & & \\
\hline $\mathbf{P g} \_\mathbf{h}$ & 0,037 & ns & 0,106 & ns & 0,195 & * & 0,685 & $* *$ & 0,892 & $* *$ & 0,823 & $* *$ \\
\hline \multicolumn{13}{|l|}{ Gn_h } \\
\hline \multicolumn{13}{|l|}{ Me_h } \\
\hline Sena_v & 0,287 & ns & & & & & & & & & $-1,769$ & ns \\
\hline A_v & $-0,228$ & ns & & & & & & & & & 1,474 & ns \\
\hline \multicolumn{13}{|l|}{$P g \_v$} \\
\hline \multicolumn{13}{|l|}{ Gn_v } \\
\hline Me_v & & & & & $-0,174$ & ns & & & & & & \\
\hline$F$ & 5,178 & $*$ & 2,040 & ns & 3,440 & ns & 30,339 & ** & 9,364 & ** & 6,804 & ** \\
\hline $\mathbf{R}^{2}$ & 0,742 & & 0,136 & & 0,364 & & 0,700 & & 0,609 & & 0,650 & \\
\hline
\end{tabular}

Tabela 11 - Coeficientes da equação de regressão múltipla obtida por método stepwise de seleção de variáveis para previsão do deslocamento vertical em pontos do tecido mole em função do deslocamento em pontos do tecido duro e os valores correspondentes de $\mathrm{F}$ e do coeficiente de determinação $\left(\mathrm{R}^{2}\right)$.

\begin{tabular}{|c|c|c|c|c|c|c|c|c|c|c|c|c|}
\hline \multirow{3}{*}{$\begin{array}{l}\text { Tecido Ósseo } \\
\text { Intercepto }\end{array}$} & \multicolumn{11}{|c|}{ Tecido mole } & \\
\hline & \multicolumn{2}{|l|}{ Pn_v } & \multicolumn{2}{|l|}{ Sn_v } & \multicolumn{2}{|l|}{ Ph_v } & \multicolumn{2}{|l|}{ Pgm_v } & \multirow{2}{*}{$\frac{\text { Gnm_v }}{-2,106}$} & \multicolumn{3}{|c|}{ Mem_v } \\
\hline & $-0,72$ & ns & 0,285 & ns & $-0,207$ & ns & $-4,070$ & $*$ & & ns & $-0,573$ & ns \\
\hline Sena_h & & & & & & & $-1,084$ & ns & $-0,626$ & ns & $-0,516$ & ns \\
\hline A_h & & & $-0,248$ & ns & & & 0,796 & ns & & & & \\
\hline \multicolumn{13}{|l|}{$\mathbf{P g} \_\mathbf{h}$} \\
\hline \multicolumn{13}{|l|}{ Gn_h } \\
\hline \multicolumn{13}{|l|}{ Me_h } \\
\hline Sena_v & & & $-1,150$ & ns & $-1,234$ & * & 0,587 & $* *$ & 0,669 & $* *$ & 1,390 & ns \\
\hline A_v & 0,213 & ns & 1,350 & $*$ & 1,572 & $* *$ & & & & & $-1,962$ & ns \\
\hline Pg_v & 0,159 & ns & 0,205 & ns & & & & & & & & \\
\hline Gn_v & & & & & 0,183 & ns & & & & & & \\
\hline Me_v & & & & & & & & & & & 0,474 & * \\
\hline $\mathbf{F}$ & 5,222 & * & 4,587 & $*$ & 9,826 & $* *$ & 6,343 & $* *$ & 13,089 & $* *$ & 9,737 & ** \\
\hline $\mathbf{R}^{2}$ & 0,465 & & 0,647 & & 0,728 & & 0,634 & & 0,686 & & 9,737 & \\
\hline
\end{tabular}

A tabela 8 se refere ao deslocamento horizontal no tecido mole, enquanto que a tabela 9 se refere ao deslocamento vertical no tecido mole.

Observa-se pela tabela 8 que somente são sig- nificativas as correlações lineares entre os deslocamentos de um ponto do tecido mole do terço inferior e os pontos, também do terço inferior da face do tecido ósseo. Como essas correlações são 
positivas, elas indicam que um aumento no deslocamento do tecido ósseo na direção horizontal acarreta também um aumento no deslocamento do tecido mole. Mas essa afirmativa vale somente para pares de pontos do terço inferior da face. Deve-se enfatizar que, apesar de significativos, esses coeficientes de correlação estão entre 0,64 e 0,84 , portanto são de intensidade média.

Por outro lado, as correlações entre o deslocamento horizontal ou vertical de pontos do tecido ósseo e o deslocamento vertical em pontos do tecido mole são mais evidentes entre os três pontos do terço inferior da face do tecido mole e os dois pontos do tecido ósseo do terço médio da face. Ainda assim, os coeficientes de correlação de Pearson são relativamente baixos, pois variam de 0,73 a 0,78 . Há outras correlações significativas, mas de menor intensidade ainda.

A regressão múltipla, com seleção de variáveis pelo método stepwise, foi empregada para tentar identificar a influência do deslocamento de mais de um ponto do tecido ósseo no deslocamento de um mesmo ponto do tecido mole. O resultado é apresentado nas tabelas 10 e 11 , respectivamente para o deslocamento horizontal e vertical. Com essas equações de regressão, cujos coeficientes devem ser lidos em uma coluna da tabela, é possível prever um deslocamento no ponto do tecido mole correspondente à coluna, em função dos deslocamentos em pontos do tecido ósseo, tanto horizontal como vertical. Os valores de $\mathrm{F}$ indicam se a regressão determinada pelo método de seleção de variáveis é significativa, enquanto que o coeficiente de determinação $\mathrm{R}^{2}$ representa a proporção da variação total que é explicada pela regressão. Esses coeficientes de determinação nunca foram maiores do que 0,80 e, em alguns casos, são menores do que 0,50 . Alguns coeficientes da equação de regressão são não significativos individualmente, mas, em princípio, não devem ser descartados, pois podem melhorar a previsão se utilizados em conjunto com os outros coeficientes.

Observa-se pela tabela 10 , quanto ao desloca- mento horizontal em pontos do tecido mole, que ele depende mais do deslocamento no Pg_h, especialmente os pontos do terço inferior da face. De acordo com os valores dados na tabela 11 , o deslocamento vertical em pontos do tecido mole tem uma dependência maior com o deslocamento, também vertical, no Sena_v ou A_v, principalmente os pontos do terço inferior da face. Esse resultado, de alguma forma, já foi identificado pelos coeficientes de correlação de Pearson dados anteriormente.

\section{DISCUSSÃO}

O tratamento da má oclusão Classe III esquelética envolve um planejamento multidisciplinar que leva a alterações funcionais e estéticas do complexo maxilo-mandibular. No presente trabalho foram avaliados pacientes com má oclusão semelhantes, cuja terapia foi semelhante visando a padronização da amostra. Este tipo de situação, que leva em consideração o padrão esquelético dos pacientes tratados ${ }^{15}$, acarretou em tipos de movimentos cirúrgicos semelhantes das bases ósseas. A direção dos movimentos cirúrgicos para o maxilar superior e inferior foi basicamente a mesma em todos os casos. A maxila foi deslocada para cima, (impactada) e para frente (avançada) e sofreu rotação anti-horária e a mandíbula que foi deslocada para trás (reduzida) e rotacionada no sentido anti-horário.

A metodologia empregada para obtenção dos dados neste estudo foi descrita anteriormente pela maioria dos autores que utilizaram a base craniana como referência e a sobreposição de cefalogramas como método empregado para análise deste tipo de avaliação. A técnica para mensuração das medidas que estavam sujeitas a menor interferência ou variação foi o método computadorizado, que oferece melhores recursos no que diz respeito à localização, manipulação e comparação entre os cefalogramas.

A técnica cirúrgica utilizada nos casos onde foi realizada a mentoplastia foi a osteotomia horizontal deslizante da borda anterior da mandíbula, que 
produz resultados previsíveis e estáveis a longo prazo $3,37,38,44$, entretanto pode provocar uma variação na resposta tecidual quanto é levada em consideração a quantidade de desinserção muscular e o local das osteotomias $46,48,59$.

Diversos autores $5,25,34,41,47,45$ que descrevem a dificuldade na previsão do deslocamento do perfil facial, principalmente na região do maxilar superior, atribuem esta variação ao local e inclinações das osteotomias 26,57 , variação de tônus muscular, espessura, além de manipulação dos tecidos moles seguida de fibrose cicatricial ${ }^{60}$.

Comparando-se a população hispânica com a americano-européia pode ser verificado que as diferenças étnicas também estavam presentes e que os planejamentos deveriam ser individualizados ${ }^{9}$.

Visando diminuir esta variação foi adotado o critério de que todos os pacientes pertencentes à amostra tivessem sido operados pelo mesmo cirurgião, sendo que o planejamento foi realizado pela mesma pessoa seguindo critérios semelhantes e padronizados. Todos os pacientes receberam fixação interna rígida, que notadamente está menos sujeita às variações provocadas por um certo grau de recidiva ${ }^{6,7}$ esperado no tratamento da má oclusão esquelética da Classe III, receberam ainda reconstrução nasolabial através da sutura da base alar e em $V Y^{10,19,24,60}$.

Além dos procedimentos descritos, todos os pacientes terminaram a terapia pós-cirúrgica buscando o melhor relacionamento entre suas bases ósseas, corrigidas com as inclinações radiculares previstas para o final do tratamento, e a oclusão obtida foi estabilizada por meio de contenção ortodôntica pós tratamento ${ }^{28}$.

Foi realizado o teste $t$ de Student para a comparação do intra-grupo para os pacientes tratados com mentoplastia associada e o grupo tratado sem mentoplastia, sendo adotado um nível de significância de 5\%. Não foi possível constatar que os indivíduos tratados com e sem mentoplastia produzam deslocamentos médios diferentes (Tab. 4, 5). Em nosso estudo o ponto pogônio demonstrou uma menor variação, mesmo nos casos onde não foi realizada mentoplastia. Os deslocamentos para esta região mostraram-se semelhantes na maioria dos casos. Foi possivel observar que a resposta do perfil facial, frente ao deslocamento ósseo no sentido horizontal, apresentou correlação significante para os pontos Pg e Pgm ( $\mathrm{r}=0,84)$, Pg e Gnm $(r=0,74)$. Para avaliação dos deslocamentos foi realizado o estudo das correlações no sentido horizontal entre os pontos de tecido ósseo e tecido mole, onde foi possível constatar que os pontos de tecido ósseo na maxila tiveram correlações fracas no sentido horizontal com o tecido mole desta região e que houve correlação de moderada a fraca, significativa no ponto A com o ponto Pn e Gnm. Os pontos do tecido ósseo mandibular tiveram uma correlação significativa, porém moderada com os pontos do terço médio da face e uma correlação forte e altamente significativa com os pontos no terço inferior. No sentido vertical os pontos situados no terço médio da face e inferior tiveram correlação com as alterações horizontais do terço médio e inferior do perfil facial ( Tab. 8).

Os pontos localizados no osso mandibular ( $\mathrm{Pg}$, $\mathrm{Gn}, \mathrm{Me}$ ) não tiveram correlação com as alterações verticais do terço médio e inferior da face. Os pontos Sena e A, também no sentido vertical, tiveram correlações significativas com os pontos $\mathrm{Pn}, \mathrm{Sn}$ e $\mathrm{Ph}$ e tiveram correlações significativas com os pontos de tecido mole Pgm, Gnm e Mem ( Tab. 11).

Os pontos de tecido ósseo maxilar (Sena, A) tiveram, no sentido horizontal, correlações significantes, mas fracas com a região sub nasal e o ponto Sena, no sentido horizontal, teve correlação fraca com o ponto $\mathrm{Ph}$, no sentido vertical, e Gnm, no sentido vertical.

As correlações entre o deslocamento horizontal dos pontos do tecido ósseo e o deslocamento vertical nos pontos do perfil facial tiveram relação significativa, porém de baixa intensidade entre os pontos Pgm, Mem e Gnm e os pontos no tecido ósseo (Sena e A) do terço médio da face. 
O movimento vertical dos pontos mandibulares foi significativo, mas foram correlacionados moderadamente com os pontos do terço médio da face $(\mathrm{Sn}, \mathrm{Pn}, \mathrm{Ph})$ e apenas o movimento vertical dos pontos de tecido ósseo mandibular (Pgm, Gnm, Mem) tiveram uma correlação significativa com o ponto Mem no sentido vertical e correlação fraca ou não significativa com Pgm e Gnm (Tab. 11).

A regressão múltipla foi empregada para tentar identificar a influência do deslocamento de mais de um ponto do tecido ósseo no deslocamento de um mesmo ponto do tecido mole.

Neste trabalho houve a participação do ortodontista e do cirurgião buco-maxilo-facial no diagnóstico e planejamento cirúrgico, o que é recomendado por muitos autores $7,12,14,23,32,33$.

Os principais objetivos do tratamento das deformidades dentofaciais é a obtenção da proporcionalidade dos tecidos moles da face $e^{34,55}$ e isto pode ser obtido com o planejamento e a execução da técnica de cirurgia ortognática. Também, como resultado da cirurgia ortognática, foi obtida uma melhora funcional da mastigação, fonação, respiração e oclusão ${ }^{16,39,45,47,48}$.

\section{CONCLUSÃO}

a) Os deslocamentos médios dos pontos do perfil facial nos indivíduos tratados com mentoplastia e sem mentoplastia foram semelhantes.

b) Houve correlação fortemente significante dos pontos Pg e Pgm, no sentido horizontal, e Me e Mem, no sentido vertical.

c) Houve baixa correlação entre os pontos Sena e A, no sentido horizontal, com os pontos $\mathrm{Pn}, \mathrm{Sn}$ e Ph.

d) O deslocamento dos pontos no sentido vertical foi mais evidente entre os pontos $\mathrm{Pg}$, Gn e Me e os pontos A e Sena, porém com correlações de baixa intensidade.

e) O deslocamento do ponto pogônio, no sentido horizontal, influencia horizontalmente os pontos do terço inferior da face. O deslocamento dos pontos Sena e A, no sentido vertical, influencia verticalmente os pontos do terço facial inferior, principalmente.

\title{
Cephalometric study of the facial profile changes in Class III patients submitted to bimaxillary orthognathic surgery
}

\begin{abstract}
The present study evaluated the facial profile modifications in 15 skeletal Class III patients that were submitted to presurgical orthodontic treatment and orthognathic bimaxillary surgery stabilized with a rigid fixation. Eight of the patients have undergone to genioplastic surgery. Presurgical (T1) and late postsurgical (T2) radiographs taken apart with a minimum of 6 month interval had been used. The horizontal and vertical displacement of skeletal and soft tissue profile points were analyzed. The comparison of the cases submitted or not to a genioplastic surgery (t Test) showed no differences for the displacement of the skeletal and soft tissue points. The multiple linear regression analysis showed a significant correlation for horizontal movements of the Pg and Pgm points and for vertical movements of the Me and Mem points. A low correlation was found for the horizontal movements of Sena and A points and for $\mathrm{Pn}, \mathrm{Sn}$ and $\mathrm{Ph}$ points. The vertical movements were more evident for the points $\mathrm{Pg}, \mathrm{Gn}$, and Me and for the A and Sena points but also showed low correlation.
\end{abstract}

Key words: Skeletal Class III. Facial Profile. Orthognathic surgery. 


\section{REFERÊNCIAS}

1. ARAÚJO, A.; SCHENDEL, S. A.; WOLFORD, L. M.; EPKER, B. $\mathrm{N}$. Total maxillary advancement with and without bone grafting. J Oral Surg, Chicago, v. 36, p. 849-858, 1978.

2. ARNETT, G. W.; BERGMAN, R. T. Facial Keys to orthodontic diagnosis and treatment planning. Part II. Am J Orthod Dentofacial Orthop, St. Louis, v. 103, p. 395-411, 1993.

3. AYOUB, A. F.; STIRRUPS, D. R.; MOOS, K. F. Evaluation of changes following advancement genioplasty using finite element analysis. Int J Oral Maxillofac Surg, Copenhagen, v. 31, p. 217-222, 1993.

4. BELL, W. H. Correction of mandibular prognathism by mandibular setback and advancement genioplasty. Int J Oral Surg, Copenhagen, v. 10, p. 221-229, 1981

5. BELL, W. H.; DANN, J. J. Correction of dentofacial deformities by surgery in the anterior part of the jaws. A study of stability and soft tissue changes. Am J Orthod, St. Louis, v. 64, p. $162-187,1973$

6. BELL, W. H.; SCHEIDEMAN, G. B. Correction of vertical maxillary deficiency: stability and soft tissue changes. J Oral Surg, Chicago, v. 39, p. 666-670,1981.

7. BETTS, N. J.; FONSECA, R. J. Soft tissue changes associated with orthognathic surgery. In: BELL, William H. Modern practice orthognathic and reconstructive surgey. [S. I.]: WB Saunders, 1992. p. 2171

8. CARLOTTI, A. E.; ASCHAFFENBURG, P. H.; SCHENDEL, S. A. Facial changes associated with surgical advancement of the lip and maxilar. J Oral Maxillofac Surg, Philadelphia, v. 44, p. 593-596, 1986.

9. CLEMENTE-PANICHELLA, D.; SUZUKI, S.; CISNEROS, G. J.; Soft to hard tissue movement ratios: orthognathic surgery in a hispanic population. J Adult Orthod Orthognath Surg, Chicago, v. 4, p. 255-264, 2000.

10. COELHO, U. Efeito da sutura em duplo VY, associada à suturas das bases alares, sobre o lábio superior, após o avanço da maxila: estudo cefalométrico comparativo. $1995.110 \mathrm{f}$. Dissertação ( Mestrado) - Faculdade de Odontologia da Universidade Estadual Paulista Júlio de Mesquita Filho, Araraquara, 1995.

11. COLLINS, P. C.; EPKER, B. N. The alar base cinch: a technique for prevention of alar base flaring secondary to maxillary surgery. Oral Med Pathol, Copenhagen, v. 53, p. 549-553, 1982.

12. DANN, J. J.; FONSECA, R.; BELL ,W. H. Soft tissue changes associated with total maxillary advancement: a preliminary study. J Oral Surg, Chicago, v. 34, p. 19-23, 1976.

13. DAL PONT, G. Retromolar osteotomy for correction of prognathism. J Oral Surg, Chicago, v. 19, p. 42-47, 1961

14. ENACAR, A.; TANER, T.; TOROGLU, S. Analysis of soft tissue profile changes associated with mandibular setback and double-jaw surgeries. Int J Adult Orthod Orthognath Surg, Chicago, v. 14 , p. $27-35,1999$

15. ENLOW, D. H. Variações normais na forma facial. In: ENLOW, Donald H.; POSTON, William Roger. Crescimento facial. 3. ed. São Paulo: Artes Médicas, 1993. p. 209-212.

16. EPKER, B. N. Modifications in the sagittal osteotomy of the mandible. J Oral Surg, Chicago, v. 35, p. 157-159, 1977.

17. EPKER, B. N.; WOLFORD, L. M.; FISH, L. C. Mandibular deficiency syndrome II - Surgical considerations for mandibular advancement. J Oral Surg, Chicago, v. 45, p. 348-363, 1978.

18. FROMM, B.; LUNDBERG, M. The soft-tissue facial profile before and after surgical correction of mandibular protusion. Dental Aktieselskabet, [S. I.], v. 16, no. 42, p. 157-177, 1969

19. GABRIELLI, M. F. R. Alterações de posição dos tecidos moles da face após osteotomias Le Fort I: estudo retrospectivo. 1990. 77 f. Tese (Livre-Docente) - Faculdade de Odontologia da Universidade Estadual Paulista Júlio de Mesquita Filho, Araraquara, 1990

20. GAGGL, A.; SCHULTES, G.; KARCHER, H. Changes in soft tissue profile after sagittal split ramus osteotomy and retropositioning of the mandibule. J Oral Maxillofac Surg, Philadelphia, v. 57, p. 542-546, 1999.
21. GALLAGHER, D. M.; BELL, W. H.; STORUM, K. A. Soft tissue changes associated with advancement genioplasty performed concomitantly with superior repostioning of the maxilla. J Ora Maxillofac Surg, Philadelphia, v. 42, p. 238-242, 1984

22. GIMENES, P. P. Avaliação cefalométrica das alterações labiais de indivíduos dolicocefálicos portadores de maloclusão classe III, tratados com cirurgia ortognática bimaxilar. $154 \mathrm{f}$. Dissertação (Mestrado) - Faculdade de Odontologia da Universidade Estadual Paulista Júlio de Mesquita Filho, Araraquara, 2002.

23. GONÇALVES, J. R.; SANTOS-PINTO, A.; MARTINS, L. P.; PORCIÚNCULA, H. F.; MANSUR, D. J.; TAVARES, H. S. Estabilidade após avanço mandibular. R Dental Press Ortodon Ortop Facial, Maringá, v. 4, p. 51-57, 1999.

24. GUYMON, M.; CROSBY, D. R.; WOLFORD, L. M. The alar base cinch suture to control nasal width in maxillary osteotomies. Int J Adult Orthognath Surg, Chicago, v. 3, p. 899-895, 1988.

25. HERSHEY, H. G.; SMITH, H. Soft-tissue profile change associated with surgical correction of the prognathic mandible. Am J Orthod, St. Louis, v. 5, no. 65, p. 483-502,1974.

26. HOFFMAN, G. R.; MOLONEY, F. B. The stability of facial osteotomies. 3. Chin advancement. Aust Dent J, Sydney, v. 40, p. 289-295, 1995.

27. HUNSUCK, E. E. A modified intraoral sagittal splitting tecnique for correction of mandibular prognathism. J Oral Surg, Chicago, v. 26, p. 249-252, 1968

28. JACOBS, J. D. Princípios de mecânica ortodôntica em casos cirúrgicos. Rev Straight-Wire Brasil, Campinas, v. 4, p. 13-16, 1994.

29. INGERVALL, B.; THUER, U.; VUILLEMIN, T. Stability and effect on the soft tissue profile of mandibular setback with sagittal split osteotomy and rigid internal fixation. Int J Adult Orthodon Orthognath Surg, Chicago, v. 10, p. 15-25, 1995.

30. KAJIKAWA, Y. Changes in soft tissue profile after surgical correction of skeletal Class III malocclusion. J Oral Surg, Chicago, v. 37, p. $167-174,1979$

31. LEE, D.; BAILEY, L.; PROFFIT, W. Soft tissues changes after superior repositioning of the maxilla with Le Fort I osteotomy: 5 year follow-up. Int J Adult Orthodon Orthognath Surg, Chicago, v. 11, no. 4, p. 301-311, 1996.

32. LIN, S. S.; KERR, J. S. Soft and hard tissue changes in Class III patients treated by bimaxillary surgery. Eur J Orthod, London, v. 20 , p. $25-33,1998$

33. LINES, P. A.; STEINHAUSER, E. W. Soft tissue changes in relationship to movement of hard structures in orthognathic surgery: a preliminary report. J Oral Surg, Chicago, v. 32, p. 891-896, 1974.

34. MANSOUR, S.; BURSTONE, C. J.; LEGAN, H. L. An evaluation of soft tissue changes resulting from Le Fort I maxillary surgery. J Orthod, London, v. 84, p. 37-47, 1983.

35. MEDEIROS, P. J.; QUINTÃO, C. C. A. A.; MENEZES, L. M. Avaliação da estabilidade do perfil facial após tratamento orto-cirúrgico. Ortodontia Gaúcha, Porto Alegre, v. 1, p. 5-23, 1999.

36. McCANCE, A. M.; MOSS, J. P.; FRIGHT, W. R.; LINNEY, D. R. $J$. A three dimensional analysis of soft and hard tissue changes following bimaxillary orthognathic surgery in skeletal Class III patients. Br J Oral Maxillofac Surg, Edinburgh, v. 30, p. 305-312, 1992.

37. McCARTHY, J. G.; RUFF, G. L.; ZIDE, M. A surgical system for the correction of bony chin deformity. Clin Plast Surg, Philadelphia, v. 18, p. 139-152, 1991.

38. McDONNELL, J. P.; McNEIL, R. W.; WEST, R. A. Advancement genioplasty: a retrospective cephalometric analysis of osseous and soft tissue changes. J Oral Surg, Chicago, v. 35, p. 640-647, 1977

39. MOGAVERO, F. J.; BUSCHANG, P. H.; WOLFORD, L. M. Orthognathic surgery effects on maxillary growth in patients with vertical maxillary excess. Am J Orthod Dentofacial Orthop, St. Louis, v. 3, p. 288-296, 1997. 
40. MOBARAK, K. A. KROGSTAD, O.: ESPELAND, L.: LYBERG, T. Factors influencing the predictability of soft tissue profile changes following mandibular setback surgery. Angle Orthod, Appleton, v. 71, p. 216-227, 2001

41. NADKARNI, P. G. Soft tissue profile changes associated with orthognathic surgery for bimaxillary protrusion. J Oral Maxillofac Surg, Copenhagen, v. 44, p. 851-854, 1996.

42. PARK, H. S.; ELLIS, E.; FONSECA, R. J.; REYNOLDS, S. T.; MAYO, H. S. A retrospective study of advancement genioplasty. Oral Surg Med Pathol, St. Louis, v. 67, p. 481- 489, 1989.

43. POLIDO, W. D.; REGIS, L. C.; BELL, W. H. Bone resorption, stability and soft tissue changes following advancement genioplasty. J Oral Maxillofac Surg, Philadelphia, v. 49, p. 251-256, 1991.

44. POLIDO, W. D.; BELL, W. H. Long-term osseous and soft tissue changes after large chin advancements. J Craniomaxillofac Surg, Stuttgart, v. 21, p. 54-59, 1993.

45. RADNEY, L. J.; JACOBS, J. D. Soft tissue changes associated with surgical maxillary Intrusion. Am J Orthod, St. Louis, v. 80, p. 191-212, 1981.

46. REYNEKE, J. P.; JOHNSTON, T.; LINDEN, W. J. Van der. Screw osteosynthesis compared with wire osteosynthesis in advancement genioplasty: a retrospective study of skeletal stability. $\mathbf{B r} \mathbf{J}$ Oral Maxillofac Surg, Edinburgh, v. 35, p. 352-356, 1997.

47. ROBINSON, S. W.; SPEIDEL, T. M.; ISAACSON, R. J.; WORMS, F. W. Soft tissue profile change produced by reduction of mandibular prognathism. Angle Orthod, Appleton, v. 42, p. 227-235, 1972.

48. ROSEN, H. M. Aesthetic guidelines in genioplasty: the role of facial disproportion. Plast Reconstr Surg, Baltimore, v. 95, p. 463-472, 1995.

49. ROSEN, H. M. Lip-nasal aesthetics following Le Fort I osteotomy. Plast Reconstr Surg, Baltimore, v. 81, p. 171-182, 1988.

50. SARVER, D.; WEISSMAN, S. Long-term solft tissue response to Le Frot I maxillary superior repositining. Angle Orthod, Appleton, v. 4, no. 61, p. 267-276, 1991.

51. SAKIMA,T.; SACHEDEVA, R. Soft tissue response to Le Fort I maxillary impaction surgery. Int J Adult Orthodon Orthog Surg, Chicago, v. 2, p. 221-231, 1987.
52. SINCLAIR, P. M. TUCKER, M. R. Ammon complications in orthognathic surgery. J Clin Orthod, Boulder, v. 27, p. 385-397, 1993.

53. SCHENDEL, S. A.; EISENFELD, J. H.; BELL, W.H.; EPKER, B. N. superior repositioning of the maxilla: stability and soft tissueosseous relations. Am J Orthod, St. Louis, v. 70, p. 663-674, 1976.

54. SCHENDEL, S. A.; WILLIAMSON, L. W. Muscle reorientation following superior repositioning of the maxilla. J Oral Maxillofac Surg, Philadelphia, v. 41, p. 235-240, 1983.

55. SCHEIDEMAN, G. B.; LEGAN, H. L.; BELL, W. H. Soft tissue changes with combined mandibular set back and advancement geniplasty. J Oral Surg, Chicago, v. 39, p. 505-509, 1981.

56. SCHOW, S. R.; STEIN, S. M.; CARDENAS, L. Intraoperative control and stabilization of the distal osseous segment in genioplasty. J Oral Maxillofac Surg, Philadelphia, v. 53, p. 481-482, 1995.

57. SHOSHANI, Y.; CHAUSHU, G.; TAICHER, S. The influence of the osteotomy slope on bony changes after advancement genioplasty. J Oral Maxillofac Surg, Philadelphia, v. 56, p. 919-923, 1998.

58. STELLA, J. P.; STREATER, M.; EPKER, B. N.; SINN, D. Predictability of upper lip soft tissue changes with maxillary advancement. J Oral Maxillofac Surg, Philadelphia, v. 47, p. 697-703, 1989

59. VAN SICKELS, J. E.; SMITH, C. V.; TINER, B. D. Hard and soft tissue predictability with advancement genioplasty. Oral Med Pathol, Copenhagen, v. 77, p. 218-221,1994.

60. WOLFORD, L. M. Lip-nasal aesthetics following Le fort I osteotomy. Plast Reconstr Surg, Baltimore, v. 81, p. 180-182,1988.

61. WOLFORD, L. M.; CHEMELLO, P. D.; HILLIHARD, F. W. Occlusal plane alteration in orthognathic surgery. J Oral Maxillofac Surg, Philadelphia, v. 51, p. 730-740, 1993.

62. ZHOU, Y. H.; HAGG, U.; RABIE, A. B. M. Patient satisfaction following orthognathic surgical correction of skeletal Class III malocclusion. Int J Adult Orhtodon Orthognath Surg, Chicago, v. 2, no.16, p. 99-107, 2001.
Endereço para correspondência

Hewerson Santos Tavares

Instituto de Química UNESP - Araraquara

Rua Francisco Degni, s/n Bairro Quitandinha

Araraquara/SP

CEP:14.800-900

E-mail: hewersontavares@ig.com.br 